Article

\title{
Synthesis of New Chitosan from an Endemic Chilean Crayfish Exoskeleton (Parastacus Pugnax): Physicochemical and Biological Properties
}

\author{
César Burgos-Díaz ${ }^{1} * \mathbb{D}$, Mauricio Opazo-Navarrete ${ }^{1}$, José Luis Palacios ${ }^{2} \mathbb{D}$, Tamara Barahona ${ }^{1}$, \\ Yohanna Mosi-Roa ${ }^{1}$, Fresia Anguita-Barrales ${ }^{1}$ and Mariela Bustamante ${ }^{3}$ \\ 1 Agriaquaculture Nutritional Genomic Center (CGNA), Temuco 4780000, Chile; \\ mauricio.opazo@cgna.cl (M.O.-N.); tamara.barahona@gmail.com (T.B.); yohanna.mosi@cgna.cl (Y.M.-R.); \\ fresia.anguita@cgna.cl (F.A.-B.) \\ 2 Centro de Estudios en Ciencia y Tecnología de los Alimentos (CECTA), Universidad de Santiago de Chile, \\ Santiago 9170201, Chile; jose.palacios@usach.cl \\ 3 Department of Chemical Engineering, Scientific and Technological Bioresource Nucleus (BIOREN), \\ Universidad de La Frontera, Temuco 4780000, Chile; mariela.bustamante@ufrontera.cl \\ * Correspondence: cesar.burgos@cgna.cl; Tel.: +56-452740405
}

check for updates

Citation: Burgos-Díaz, C.;

Opazo-Navarrete, M.; Palacios, J.L.; Barahona, T.; Mosi-Roa, Y.; Anguita-Barrales, F.; Bustamante, M. Synthesis of New Chitosan from an Endemic Chilean Crayfish

Exoskeleton (Parastacus Pugnax): Physicochemical and Biological Properties. Polymers 2021, 13, 2304. https://doi.org/10.3390/ polym13142304

Academic Editor: Jose Manuel Ageitos

Received: 22 June 2021

Accepted: 12 July 2021

Published: 14 July 2021

Publisher's Note: MDPI stays neutral with regard to jurisdictional claims in published maps and institutional affiliations.

Copyright: (C) 2021 by the authors Licensee MDPI, Basel, Switzerland. This article is an open access article distributed under the terms and conditions of the Creative Commons Attribution (CC BY) license (https:// creativecommons.org/licenses/by/ $4.0 /)$

\begin{abstract}
Chitin is one of the most abundant natural polysaccharides in the world and it is mainly used to produce chitosan by a deacetylation process. In the present study, the extraction of chitin and chitosan from the Parastacus pugnax (P. pugnax) crayfish exoskeleton was studied for the first time. Thus, the P. pugnax crayfish exoskeleton was converted to chitosan following the steps of depigmentation, deproteinization, and deacetylation. The produced chitosan (Chitosan-CGNA) was characterized in terms of the protein content, solubility, degree of deacetylation, viscosity, molecular weight, FTIR, SEM, XRD, antimicrobial, and antioxidant activity. The results showed that the obtained chitosan had a high degree of deacetylation $(91.55 \%)$ and a medium molecular weight $(589.43 \mathrm{kDa})$. The antibacterial activity of the chitosan was tested against bacterial strains relevant for the food industry and the lowest minimum inhibitory concentration (MIC) values were evidenced with Salmonella tiphymurium (S. typhimurium), Staphylococcus aureus (S. aureus), Enterococcus faecalis (E. faecalis) and Listeria. Monocytogenes (L. monocytogenes). Moreover, the Chitosan-CGNA showed an effect on DPPH radical scavenging activity, and its antioxidant activity was dependent on concentration and deacetylation degree. These results suggest that P. pugnax exoskeleton could be an excellent natural source for the production of chitosan with potential applications in the health system, and to prevent infections associated with pathogens strains.
\end{abstract}

Keywords: chitin; chitosan; biopolymer; Parastacus pugnax; antibacterial properties; antioxidant properties

\section{Introduction}

The burrowing crayfish (Parastacus pugnax) is endemic to central-southern Chile and is found continuously between the Aconcagua River in the Valparaíso Region and the town of Nehuentué in La Araucanía Region, Chile [1]. Parastacus pugnax is one of six species of the family Parastacidae inhabiting the fresh rivers of Chile, which supports the greatest extraction effort for human consumption [2]. Moreover, Parastacus Pugnax is a very valuable natural resource for smallholder farmers from southern Chile (e.g., La Araucanía), which is exploited in a sustainable way for consumption and commercialization by local communities.

During the Parastacus Pugnax crayfish processing and consumption, a large number of by-products such as the exoskeleton, skin, and viscera are produced and usually discarded. The improper disposal of these by-products can result in environmental problems such as unpleasant odor and sedimentation of minerals in landfill [3]. Hence, conversion of the P. pugnax shrimp exoskeleton waste material into valuable added products is a great 
opportunity to mitigate environmental problems. In addition, the valorization of fishery discarded by-products has received much attention due to the increasing awareness of its economic potential and environmental impacts [4].

In recent years, there has been a growing interest in developing natural alternatives to synthetic polymers obtained from renewable resources to develop environmentally friendly materials. Among these biopolymers, chitosan has attracted the attention of both scientists and industry due to its numerous potential applications in different industrial fields [5]. Chitosan is the only naturally occurring cationic polysaccharide. It is derived from the alkaline deacetylation of chitin, which is the second most abundant biopolymer after cellulose [6]. Chitin is naturally present as a structural element in the exoskeletons of a wide range of eukaryotic organisms like crustaceans, insects, and cell walls of fungi, and the second most abundant biopolymer next to cellulose on the planet [7].

Recently, there has been great interest in the extraction of chitosan from crustacean by-products for nutraceutical and food packing applications [8]. This can be explained by its percentage of chitin (between 10 and 25\%, dried weight basis) in the crustacean shell or exoskeleton, which can be capitalized upon in the production of this economically viable natural macromolecule [9]. However, to date, there have been no studies about the extraction, characterization and properties of chitosan from the endemic Chilean crayfish (P. pugnax) exoskeleton.

Chitosan is considered a bioactive polymer with a wide variety of applications due to its biocompatibility, antibacterial activity, non-toxicity, ease of modification, and biodegradability [10]. Therefore, chitosan has been used in a wide variety of industrial fields such as biomedicine, cosmetology, papermaking, food industry, wastewater treatment, agriculture, textile industry and pharmaceutical applications, among others [5,10].

Regarding biological properties, chitosan has been found to possess antioxidant, hypocholesterolemic and antibacterial activities. The biological activities of chitosan are related to its molecular size, deacetylation and sources [11]. For instance, the antioxidant activity of chitosan and its derivatives has attracted great attention. Antioxidant activity is one of the well-known functionalities of chitosan and many studies have shown that chitosan inhibits the reactive oxygen species (ROS) and prevents lipid oxidation in food and biological systems [11].

Additionally, several studies have suggested that the antimicrobial activity of chitosan is a consequence of its cationic nature. The electrostatic interaction between positively charged $\mathrm{R}-\mathrm{N}\left(\mathrm{CH}_{3}\right)_{3}{ }^{+}$sites and negatively charged microbial cell membranes is predicted to be responsible for cellular lysis and is assumed to be the main antimicrobial mechanism [12].

The deacetylation degree (DD) of chitosan is one of the most important factors influencing both chemical (solubility, flexibility, polymer conformation, viscosity, crystallinity, high surface area, porosity, tensile strength, conductivity, photoluminescence) and biological properties (biodegradability, biocompatibility, mucoadhesion, hemostatic, analgesic, adsorption enhancer, antimicrobial, anticholesterolemic and antioxidant), which vary with processing conditions [13].

Consequently, this study proposed for the first time the extraction of chitosan from the exoskeleton of an endemic Chilean river crayfish (P. pugnax). Thus, the chitosan sample was characterized regarding their physicochemical and biological properties. Regarding biological properties of chitosan, these were studied in terms of antibacterial activity against strain bacteria of food industrial relevance and antioxidant activity.

\section{Materials and Methods}

\subsection{Materials}

The Parastacus pugnax crayfish exoskeletons were provided by "Cooperativa Agricola Cacike Juan Currimil de Lolocura Ltd.a." (Carahue, La Araucanía, Chile). Commercial chitosan was purchased from a local supplier (Citrex, La Cruz, Chile) and used as a control in this study. $\mathrm{NaOH}, \mathrm{HCl}$, ethanol, $\mathrm{NaCl}$, ascorbic acid and acetic acid were acquired from Sigma-Aldrich (São Paulo, Brazil), while trichloroacetic acid, Trolox reagent, fluores- 
cein sodium salt, Bradford reagent, Methyl orange reagent were purchased from Merck (Darmstadt, Germany). Na-phosphate buffer was purchased from J.T. Baker (Deventer, The Netherlands); AAPH from Cayman Chemical (Ann Arbor, MI, USA); DPPH reagent from Calbiochem (Darmstadt, Germany); Lactic acid from Sabores (Santiago, Chile); LAscorbic acid from Mallinckrodt (Phillipsburg, NJ, USA); Na-phosphate buffer from J T Baker (Deventer, The Netherlands); and technical Acetone from HES (Santiago, Chile).

\subsection{Extraction of Chitosan from Parastacus Pugnax Crayfish Exoskeleton}

The extraction of chitosan from P. pugnax crayfish exoskeleton was performed following the method described by Mohan et al. [3] with some modifications. Four steps were applied for chitosan preparation, including (i) demineralization, (ii) depigmentation, (iii) deproteinization and (iii) deacetylation (Figure 1). The ground P. pugnax exoskeleton powder was demineralized with $\mathrm{HCl}(4 \mathrm{M})$ for $9 \mathrm{~h}$ with a solid-to-solvent ratio of 1:10 $(w / v)$, and then depigmented with acetone for $18 \mathrm{~h}$ (overnight). After that, the sample was deproteinized with $\mathrm{NaOH}(4 \mathrm{M})$ for $7 \mathrm{~h}$ at $80^{\circ} \mathrm{C}$. After washing with distilled water until a neutral $\mathrm{pH}$ was achieved, chitin powder was dried at $40^{\circ} \mathrm{C}$ in an oven for $24 \mathrm{~h}$. Deacetylation of the chitin was achieved by reacting the chitin with $60 \% \mathrm{NaOH}(1: 30, w / v)$ at $120^{\circ} \mathrm{C}$ for $9 \mathrm{~h}$. Finally, the sample was washed with distilled water until it reached a neutral $\mathrm{pH}$, and the filtrate was dried at $40^{\circ} \mathrm{C}$ for $24 \mathrm{~h}$.

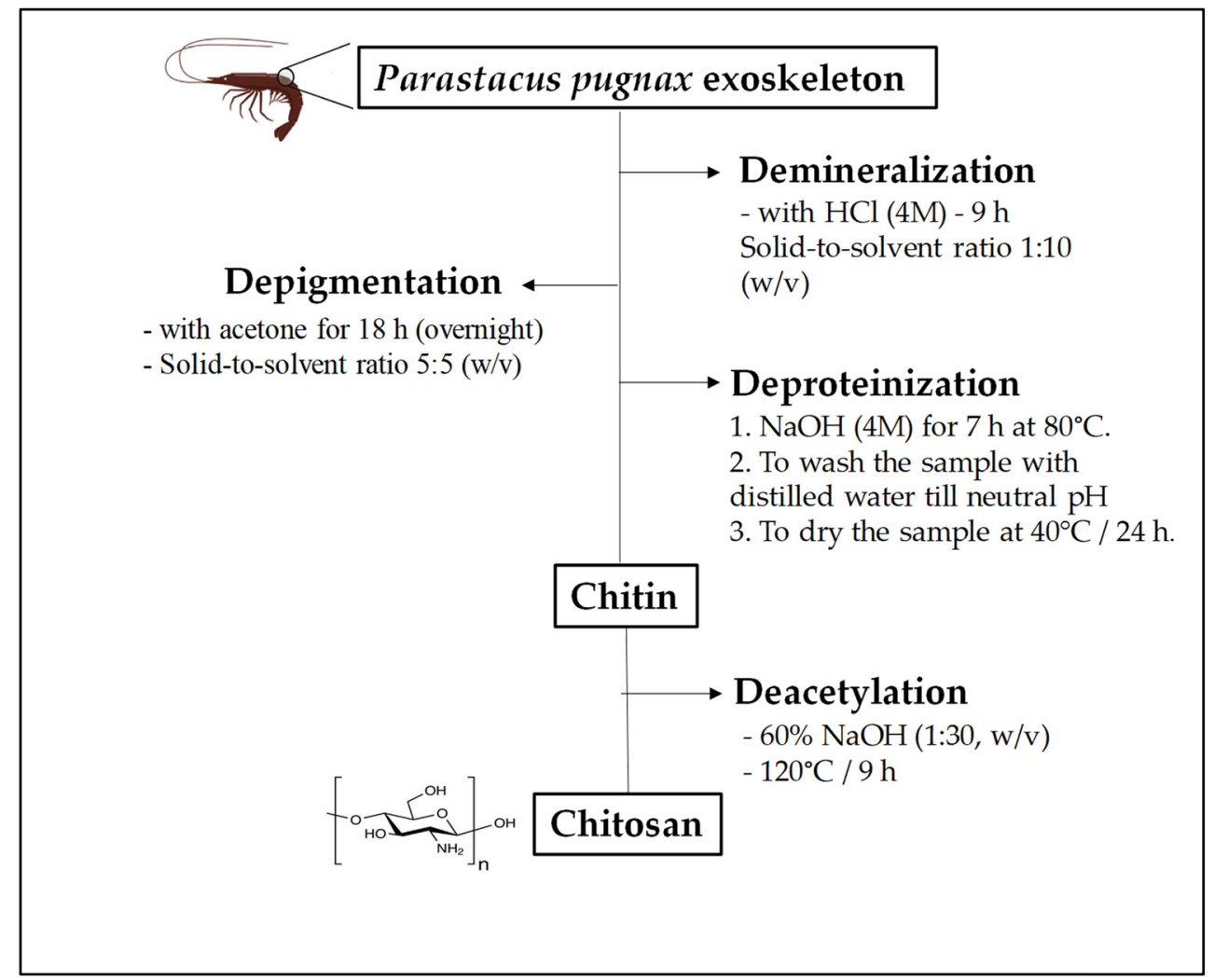

Figure 1. Diagram of production of chitosan from Parastacus pugnax exoskeleton.

\subsection{Determination of Intrinsic Viscosity and Molecular Weight (Mw)}

The molecular weight of Chitosan-CGNA and commercial CGNA were determined by using the Ubbelohde Dilution Viscometer (Cannon-Ubbelohde, State College, PA, USA) with a capillary size of $0.58 \mathrm{~nm}$. Thus, $100 \mathrm{mg}$ of chitosan was dissolved in $10 \mathrm{~mL}$ of the mixture solution of $\mathrm{CH}_{3} \mathrm{COOH}(0.1 \mathrm{M})$ and $\mathrm{NaCl}(0.2 \mathrm{M})$. The intrinsic viscosity was measured by the intercept between the Huggins (reduced viscosity, $\eta \mathrm{sp} / \mathrm{C} \sim \mathrm{C}$ ) and Kraemer (relative viscosity, $\eta \mathrm{rel} / \mathrm{C} \sim \mathrm{C}$ ) plots when the concentration was 0 . The intrinsic viscosity is 
related to molecular weight. Therefore, the molecular weight was calculated by using the Mark-Houwink Equation as follows:

$$
[\eta]=\mathrm{k}(\mathrm{Mw})^{\alpha}
$$

where $[\eta]$ is intrinsic viscosity, and $K$ and $\alpha$ are constants that are characteristic for a particular polymer-solvent system $\left(\mathrm{K}=1.81 \times 10^{-3}\right.$ and $\alpha=0.93$, respectively). " $\mathrm{Mw}$ " is the average molecular weight.

\subsection{Determination of Deacetylation Degree (DD)}

The DD of the chitosan was determined using an acid-base titration with $\mathrm{NaOH}$ $(0.1 \mathrm{M})$. First, $400 \mathrm{mg}$ of dry chitosan was dissolved in $30 \mathrm{~mL}$ of $0.1 \mathrm{M}$ hydrochloric acid solution. Methyl orange reagent was used as an indicator and a small amount was applied. The DD is equivalent to the percentage of amino groups $\left(\% \mathrm{NH}_{2}\right)$ present in the chitosan polymer chain. The DD was calculated by the following equation:

$$
\left[\% \mathrm{NH}_{2}\right]=\left[\left(\mathrm{C}_{1} \times \mathrm{V}_{1}-\mathrm{C}_{2} \times \mathrm{V}_{2}\right) \times 0.016\right] /[\mathrm{G}(100-\mathrm{W})] \times 100
$$

where $\mathrm{C}_{1}=$ Concentration $\mathrm{HCl} ; \mathrm{V}_{1}=$ Volume of $\mathrm{HCl} ; \mathrm{C}_{2}=$ Concentration $\mathrm{NaOH} ; \mathrm{V}_{2}=$ Volume $\mathrm{NaOH} ; \mathrm{G}=$ sample weight; $\mathrm{W}=$ weight of moisture content.

\subsection{Determination of Protein, Nitrogen and Ash Content of Chitosan}

The protein content of chitosan was determined by the Bradford method [14]. For this, a Bradford reagent (Merck, Darmstadt, Germany) was used. The absorbance values were measured at $595 \mathrm{~nm}$ and the assay was performed in microplate wells. The protein concentration of the sample was calculated using the equation of the standard curve. Nitrogen content was determined by Dumas combustion method (AOAC 930.03). The ash content of chitosan samples was gravimetrically estimated after the pyrolysis of $1 \mathrm{~g}$ in a muffle at $800^{\circ} \mathrm{C}$ for $5 \mathrm{~h}$. This procedure was done in triplicate and the mean ash content was calculated.

\subsection{Determination of Solubility (\%) of Chitosan}

Chitosan was dissolved in 1\% acetic acid solution and after centrifugation (Eppendorf 5810R, Hamburg, Germany), the undissolved particles were separated and dried in an oven and weighed. The solubility of the obtained chitosan was calculated from the equation:

$\%$ Solubility : $\frac{(\text { initial weight of tube }+ \text { chitosan })-(\text { final weight of tube }+ \text { chitosan })}{(\text { initial weight of tube }+ \text { chitosan })-(\text { initial weight of tube })} \times 100$

\subsection{Potentiometric Titration of Chitosan}

Potentiometric titration was used to determine the equivalent points and $\mathrm{pK}_{\mathrm{a}}$ value of chitosan. In brief, $0.2 \mathrm{~g}$ of chitosan was dissolved under stirring in $20 \mathrm{~mL}$ of $\mathrm{HCl}(0.1 \mathrm{M})$ for $48 \mathrm{~h}$ to obtain a solution of $1 \% w / v$. Then, aliquots of $0.5 \mathrm{~mL}$ of $\mathrm{NaOH}$ solution at $0.1 \mathrm{M}$ (titrant) was added to the solution and the $\mathrm{pH}$ obtained was recorded using a $\mathrm{pH}$ meter (Hanna Instruments, Woonsocket, RI, USA). The titration was stopped when the $\mathrm{pH}$ value of the solution reached a value of 12 . Then, the titration curve of $\mathrm{pH} v / s$ volume of $\mathrm{NaOH}$ consumed was plotted. At the graph of measured $\mathrm{pH}$ versus volume of $\mathrm{NaOH}$ consumed, each inflexion point was determined, where $\mathrm{V}_{1}$ corresponds to the first equivalent point, and $\mathrm{V}_{2}$ is the second equivalent point. Finally, $\mathrm{pK}_{\mathrm{a}}$ value for Chitosan-CGNA was estimated as shown in Figure 2. 
(a)

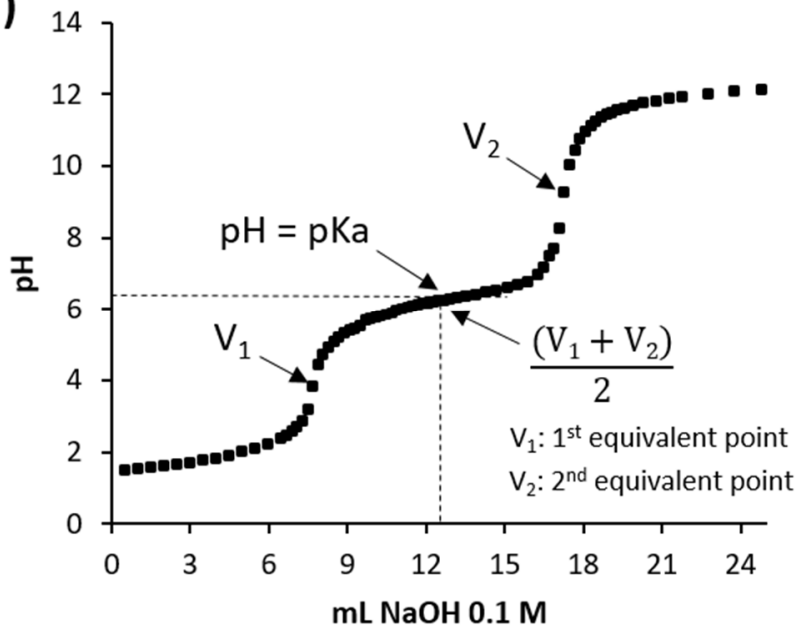

(b)

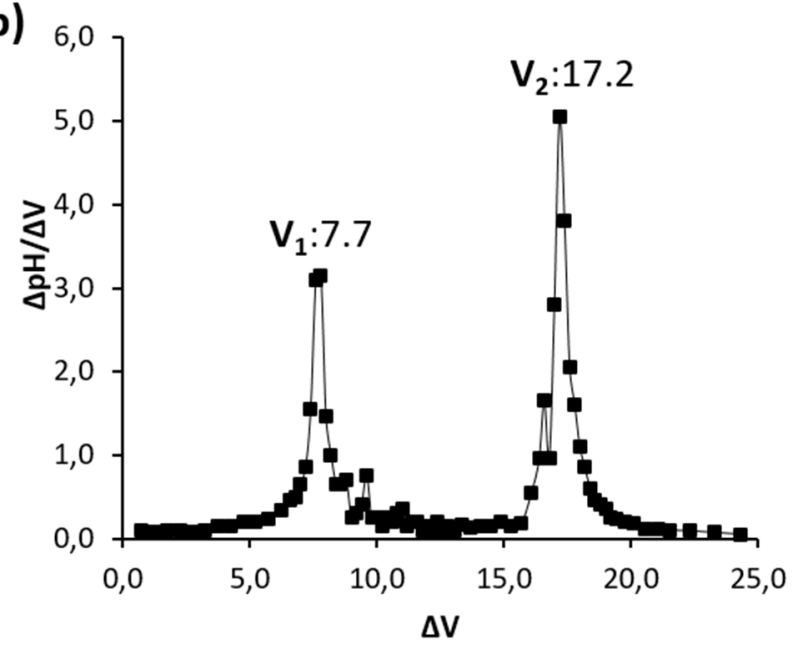

Figure 2. (a) Potentiometric titration of Chitosan-CGNA at $\mathrm{pH}$ 1.0-12.0; (b) first derivative curve of potentiometric tritation.

\subsection{Calculation of the Protonation Degree of Chitosan}

The protonation degree (DP) as a function of $\mathrm{pH}$ was calculated according to the Equation (5). The protonation degree (DP) can be defined as:

$$
\mathrm{DP}=\mathrm{C}_{\mathrm{NH}_{3}^{+}-\mathrm{R}} / \mathrm{C}
$$

where $\mathrm{C}_{\mathrm{NH} 3}{ }^{+}-\mathrm{R}$ is the concentration of protonated amine groups and $\mathrm{C}$ is the total concentration of chitosan in solution. Based on the above equation, the relationship between the $\mathrm{DP}$ and $\mathrm{pK}_{\mathrm{a}}$ is:

$$
\mathrm{pK}_{\mathrm{a}}=\mathrm{pH}-\log ((1-\mathrm{DP}) / \mathrm{DP})
$$

where $\mathrm{pK}_{\mathrm{a}}$ corresponds to the value obtained from the potentiometric titration for chitosan and DP corresponds to the degree of protonation, leaving an equation with DP as a function of $\mathrm{pH}$.

\subsection{X-ray Diffraction (XRD)}

$X$-ray diffraction spectra for commercial chitosan and Chitosan-CGNA were collected using an X-ray diffractometer (Bruker D2 PHASER, Berlin, Germany). The radiation was generated from a $\mathrm{Cu} \mathrm{K} \alpha(\lambda=1.789 \AA)$ source. The diffraction data were collected from $10^{\circ}$ to $100^{\circ}$, where $2 \theta$ is the angle of incidence of the X-ray beam on the sample.

\subsection{Scanning Electron Microscopy (SEM)}

Morphology of Chitosan-CGNA was determinated by SEM (SU3500, Hitachi, Tokyo, Japan), at acceleration voltages of $30 \mathrm{kV}, 20$ Pa vacuum and Backscattered Electron imaging (BSE).

\subsection{Estimation of Water-Solubility}

The $\mathrm{pH}$ dependence of water solubility of chitosan was evaluated from turbidity. The estimation of the solubility in water was carried out according to Qin et al. [15] with some modifications. Thus, the sample $(100 \mathrm{mg})$ was dissolved in $100 \mathrm{~mL}$ of different solutions: $1 \%(w / v)$ acetic acid, $1 \%(v / v)$ lactic acid, $1 \%(v / v) \mathrm{HCl}$. Following stepwise addition of concentrated $\mathrm{NaOH}$, the transmittance of the solution was recorded on a Multi-Detection Microplate Reader (Bio Tek Synergy HT, Winooski, VT, USA) at $600 \mathrm{~nm}$.

\subsection{DPPH Radical Scavenging Ability}

The DPPH radical scavenging activity was measured according to Huang and Tsai [8] with minor modifications. An aliquot of $0.5 \mathrm{~mL}$ of each sample solution $(2-10 \mathrm{mg} / \mathrm{mL})$ was mixed with $0.5 \mathrm{~mL}$ of DPPH $(0.1 \mathrm{mM})$ in $95 \%$ ethanol. The mixture was shaken thoroughly 
and kept in darkness at room temperature for $30 \mathrm{~min}$. The absorbance was measured using a Multi-Detection Microplate Reader (Bio Tek Synergy HT, Winooski, VT, USA) at 517 nm. Ascorbic acid was used as a positive control. The DPPH radical scavenging activity was calculated as follows:

$$
\text { DPPH radical scavenging activity }(\%)=\left(1-\mathrm{A}_{1} / \mathrm{A}_{0}\right) \times 100
$$

where $A_{0}$ is the absorbance of the control (distilled water) and $A_{1}$ is the absorbance of the sample.

\subsection{Minimum Inhibitory Concentration (MIC) Determination}

The bacterial strains were obtained from CECTA-USACH collection. To obtain the bacterial stock cultures, a single colony from each bacterial strain were isolated and growth at $35^{\circ} \mathrm{C} \pm 2(18 \mathrm{~h}, 120 \mathrm{rpm})$ in an appropriated broth, Brain Heart Infusion broth (BHI, Merck, Germany) to E. coli (ATCC 25922), S. aureus (ATCC 25923) and E. faecalis (ATCC 29212); Buffered Peptone Water (Merck, Darmstadt, Germany) to S. typhimurium (ATCC 14028); Tryptone Soya Yeast Extract Broth (Merck, Darmstadt, Germany) to L. monocytogenes (ATCC 13932); CASO broth (Merck, Darmstadt, Germany) to P. aeruginosa (ATCC 15442). To the MIC determination a subculture of each bacterial strains was obtained by inoculum from stock culture in Muller Hinton broth (Merck, Darmstadt, Germany) pH 5.5 at $35{ }^{\circ} \mathrm{C} \pm 2(18 \mathrm{~h}, 120 \mathrm{rpm})$. To the MIC determination the Chitosan-CGNA and commercial chitosan were dissolved in $0.1 \mathrm{M}$ acetic acid solution.

For MIC determination, the micro-dilution broth method was used [16,17]. Overnight subculture in MHB ( $\mathrm{pH}$ 5.5) of each bacterium were adjusted to $10^{7} \mathrm{CFU} / \mathrm{mL}$, and two-fold serial dilutions of Chitosan-CGNA and commercial chitosan were prepared in sterile MHB ( $\mathrm{pH}$ 5.5). In a 96 well microplate, $20 \mu \mathrm{L}$ of each bacteria subculture was aggregated to $120 \mu \mathrm{L}$ of different concentration of Chitosan-CGNA or commercial chitosan and incubated for $20 \mathrm{~h}$ at $35^{\circ} \mathrm{C}$ with $15 \mathrm{~min}$ of shaking at $45 \mathrm{~min}$ intervals. The MIC was determined following the Optic Density at $600 \mathrm{~nm}\left(\mathrm{OD}_{600}\right)$ to each bacterium in a Microplate Reader Synergy $^{\text {TM }}$ HTX (Figures S1 and S2). In all the assays was included a culture in MHB ( $\mathrm{pH}$ 5.5) of the respective bacteria without chitosan as negative control, and dilutions of chitosan in sterile MHB ( $\mathrm{pH}$ 5.5) without bacteria as blank. All experiments were done in triplicate. The MIC endpoint was the lowest concentration of chitosan where no $\mathrm{OD}_{600}$ increase was detected after $20 \mathrm{~h}$ of incubation.

\subsection{Minimum Bactericidal Concentration (MBC) Determination}

To the MBC determination to Chitosan-CGNA and commercial chitosan, an aliquot of $50 \mu \mathrm{L}$ from each well of the incubated microplate for the MIC determination to each bacterium was seeded on Nutrient Agar (Merck, Darmstadt, Germany) and incubated for $24 \mathrm{~h}$ at $35^{\circ} \mathrm{C}$.

The MBC was defined as the lowest concentration of chitosan that prevented any visible bacterial growth on the plate after $24 \mathrm{~h}$ incubation at $35^{\circ} \mathrm{C}$.

\subsection{Fourier Transform Infrared Spectroscopy (FTIR)}

FTIR spectra of chitosan samples were recorded in an IRPrestige-21 spectrometer (Shimadzu Corporation Pte. Ltd., Kyoto, Japan) according to Opazo-Navarrete et al. [18]. For each measurement, a total of 128 scans were collected at $4 \mathrm{~cm}^{-1}$ resolutions from 4000 to $400 \mathrm{~cm}^{-1}$, measurements were taken at room temperature using approximately $2 \mathrm{mg}$ of each sample. The samples were placed on the surface of the ATR crystal and pressed with a flat-tip plunger until spectra with suitable peaks were obtained. The measurements were repeated three times and averaged to reduce baseline effects. Between measurements, the ATR was purged with water until no chitosan signal was detectable, and then the spectra were manipulated. The spectra were smoothed with a 9-point Savitsky-Golay function and normalized second-derivative spectra were obtained with the IR-solution 
software version 1.10 (Creon Lab Control AG, Shimadzu Corporation Pte. Ltd., Kyoto, Japan). Finally, spectra were cut and analyzed.

\subsection{Statistical Analysis}

Data were expressed as means \pm standard deviations. All data were subjected to a $\mathrm{t}$-student test to compare the means between the two independent groups. Differences were considered statistically significant at $p<0.05$.

\section{Results and Discussions}

\subsection{Physicochemical Characterization of Chitosan}

3.1.1. Degree Deacetylation (DD)

The DD of chitosan samples (hereafter referred as Chitosan-CGNA and commercial chitosan, respectively) are shown in Table 1 . The chitosan obtained from P. pugnax crayfish exoskeleton reached a DD value of $91.5 \%$, which was significantly $(p<0.05)$ higher than commercial chitosan $(85.1 \%)$. The variations observed in the DD between Chitosan-CGNA and commercial chitosan (control) can be attributed to the purification methods and the reaction conditions used in this study. According to Rasweefali et al. [19], the factors that affect the DD of chitosan are the isolation method of chitin, source of extraction, species, alkaline concentration, reaction time, and temperature.

Table 1. Physicochemical characterization of chitosan samples.

\begin{tabular}{ccc}
\hline Physicochemical Properties & Chitosan-CGNA & Commercial Chitosan \\
\hline Molecular weight $(\mathrm{kDa})$ & $589.43 \pm 14.03^{\mathrm{a}}$ & $536.58 \pm 16.4^{\mathrm{b}}$ \\
Nitrogen content (\%) & $7.60 \pm 0.10^{\mathrm{a}}$ & $7.74 \pm 0.07^{\mathrm{a}}$ \\
Solubility $(\%)$ & $98.83 \pm 0.22^{\mathrm{a}}$ & $98.95 \pm 0.35^{\mathrm{a}}$ \\
Intrinsic viscosity $(\mathrm{mL} / \mathrm{g})$ & $401.46 \pm 12.71^{\mathrm{a}}$ & $385.69 \pm 18.11^{\mathrm{a}}$ \\
Deacetylation degree $(\%)$ & $91.55 \pm 0.44^{\mathrm{a}}$ & $85.11 \pm 0.40^{\mathrm{b}}$ \\
Protein content $(\%)$ & $0.5 \pm 0.03^{\mathrm{a}}$ & $0.5 \pm 0.04^{\mathrm{a}}$ \\
pK $_{\mathrm{a}}$ & 6.22 & 6.50 \\
Ash content $(\%)$ & $0.11 \pm 0.01^{\mathrm{a}}$ & $0.14 \pm 0.01^{\mathrm{b}}$ \\
Appearance & white flakes & white flakes \\
\hline
\end{tabular}

$\overline{\mathrm{a}, \mathrm{b}}$ Different superscript letters in the same row indicate a significant difference between groups $(p<0.05)$.

Yuan et al. [20] reported that the DD of chitosan is generally controlled by factors involved in the process of the native polymer with an alkali such as processing time, and temperature to obtain the highest DD (>90\%) materials. Ali et al. [21], reported a DD of $92 \%$ for mud crab chitosan using $55 \% \mathrm{NaOH}$ at $110{ }^{\circ} \mathrm{C}$. Similar conditions $(60 \%$ $\mathrm{NaOH}$ at $120^{\circ} \mathrm{C}$ ) were used in the present study for obtaining chitosan from P. pugnax crayfish exoskeleton. According to Rasweefali et al. [19], $\mathrm{NaOH}$ concentration up to $60 \%$ is suggested for obtaining chitosan with a significantly high DD. Hence, the high purity of this cationic biopolymer was influenced by the process conditions applied to obtain the chitin and, subsequently, chitosan.

The chitosan DD is one of the most important chemical parameters that determines many physiochemical and biological properties, and it influences the performance in many of its applications [22]. For instance, chitosan with a DD of $85-95 \%$ is defined as a high DD, which confers good solubility in water. While a DD of $55-70 \%$ is defined as a low DD of chitosan, being almost completely insoluble in water [23]. Most commercial chitosan samples show average DD values of 70-90\%. For some specific biological applications, chitosan with higher DD values ( $>95 \%$ ) can be produced by further deacetylation steps, which not only increases the cost of production, but often leads to partial depolymerization [24]. According to the abovementioned features, the Chitosan-CGNA could be considered as chitosan with a high purity and could be applied, for instance, in biomedicine applications. 


\subsubsection{Molecular Weight of Chitosan}

In this study, the molecular weight (Mw) of Chitosan-CGNA was $589.43 \mathrm{kDa}$, while $\mathrm{M}_{\mathrm{W}}$ of commercial chitosan was lower (536.58 kDa) (Table 1). The slight differences in the $\mathrm{M}_{\mathrm{W}}$ could be attributed to the conditions and reaction times adopted to obtain each chitosan sample. Younes et al. [25] reported that the factors affecting the average $\mathrm{Mw}$ of chitosan are the concentration of alkali, extraction process, raw material, DD, and solubility. Based on the range of its $\mathrm{Mw}$, chitosan can be classified into three different types, namely, high-molecular-weight chitosan $(>700 \mathrm{kDa})$, medium-molecular-weight chitosan (150-700 kDa), and low-molecular-weight chitosan (less than $150 \mathrm{kDa}$ ) [26]. Therefore, according to these classifications, the Chitosan-CGNA obtained in the present study would be classified as medium-molecular-weight chitosan. In general, the Mw of chitosan is one of the most significant parameters to determine its applications [19]. For instance, chitosan with medium Mw possesses anti-cancer activities, and chitosan with low Mw has antitumor, antioxidant, and antibacterial properties [19]. To date, high-molecular-weight chitosan and medium-molecular-weight have been widely used for bioplastics, flocculation, thin films and biofiber applications [26].

\subsubsection{Protein and Nitrogen Content}

The protein and nitrogen content of chitosan samples are shown in Table 1. When the Chitosan-CGNA sample was compared with the commercial sample, similar nitrogen content was observed. The nitrogen content of Chitosan-CGNA $(7.60 \pm 0.1 \%)$ was slightly lower than commercial chitosan $(7.74 \pm 0.07 \%)$ (Table 1$)$. The chitin and chitosan nitrogen generally ranged from 5 to $8 \%$, making them more attractive to several industrial applications [19]. Regarding protein content, both Chitosan-CGNA and commercial chitosan presented a similar value $(0.5 \%)$. These results indicate that the method used allows obtaining a product highly deacetylated and deproteinized.

\subsubsection{Solubility}

The Chitosan-CGNA sample showed a solubility value of $98.50 \%$ in acetic acid (1\%), and this result is similar to commercial chitosan under the study $(98.95 \%)$. The solubility and DD are important properties determining the quality of the chitosan. The factors that can influence the chitosan solubility are reaction time, temperature, size of the product, alkaline concentration and a lower deacetylation rate. Moreover, the amino groups are protonated in acid media ( $\mathrm{pK}_{\mathrm{a}}$ lower than 6.2) leading to the solubility of chitosan [19].

\subsubsection{Intrinsic Viscosity}

The intrinsic viscosity values are shown in Table 1 . The viscosity of Chitosan-CGNA and commercial chitosan were 401.46 and $385.69 \mathrm{~mL} / \mathrm{g}$, respectively. Various parameters can affect the intrinsic viscosity of chitosan, such as concentration, molar mass, solvent, temperature, shear rate, chemical structure of the polymer and DD [27]. In the case of chitosan in acidic media, the degree of dissociation of the ionic groups also is an important factor that must be considered. The presence of ionic groups in their structures leads to expansion of the polymer chains due to the electrostatic repulsions, causing an increase in viscosity [27]. It should be noted that some biological properties of chitosan depend on its viscosity [28]. For instance, Cho et al. [29] reported that the antimicrobial activity of chitosan increased with decreasing viscosity.

\subsubsection{Ash Content}

The determination of ash content is an important parameter to evaluate the effectiveness of the demineralization process of chitosan. Thus, ash content of Chitosan-CGNA and commercial chitosan were determined in this study. It is important to mention that the level of demineralization and deproteination determines the purity of chitosan, which affects its biological properties such as immunogenicity, biocompatibility and biodegradability [30]. According to Ssekatawa et al. [30], chitosan with an ash content lower than 1\% possesses su- 
perior biological properties and is recommended for biomedical applications. The chitosan obtained in this study presented an ash content of $0.11 \%$ and this value is fit for medical applications. In addition, the variation observed in the ash values between Chitosan-CGNA and commercial chitosan could be attributed to the differences in the demineralization conditions used for each chitosan (e.g., $\mathrm{HCl}$ concentration and solid-to-solvent ratio).

\subsection{Potentiometric Titration and Protonation Degree of Chitosan}

Potentiometric titration is widely used to investigate polyelectrolyte behaviour in solution. For instance, previous studies have reported the titration and precipitation behaviour of chitosan during neutralization [31]. Figure 2a shows the variation of $\mathrm{pH}$ values as a function of $\mathrm{NaOH}$ added volume for chitosan solution. It can see that the potentiometric curve shows two inflexion points, which correspond to equivalent points (indicated in the Figure 2a). The first point $\left(\mathrm{V}_{1}\right)$ corresponds to the neutralization of the excess of $\mathrm{HCl}\left(\mathrm{H}^{+}+\mathrm{OH}^{-} \rightarrow \mathrm{H}_{2} \mathrm{O}\right)$. While the second point $\left(\mathrm{V}_{2}\right)$ is attributed to the protonation of amine groups of GlcN residues of chitosan. It should be noted that the determination of the first derivative helps in a precise reading of $V_{1}$ and $V_{2}$ (equivalent points) (Figure 2b). According to Pérez-Álvarez et al. [32], in acidic $\mathrm{pH}$ 's primary amino groups are protonated, and as $\mathrm{NaOH}$ is added during titration, they are neutralized $\left(-\mathrm{NH}_{3}{ }^{+}\right.$ $+\mathrm{OH}^{-} \rightarrow-\mathrm{NH}_{2}+\mathrm{H}_{2} \mathrm{O}$ ) and their concentration can, thus, be quantified. In addition, the chitosan $\mathrm{pK}_{\mathrm{a}}$ value (6.22) was obtained from the potentiometric titration curve. This $\mathrm{pK}_{\mathrm{a}}$ value is similar to that registered by other chitosan [33].

On the other hand, potentiometric titration was performed to evaluate the $\mathrm{pH}-$ dependent ionization degree of chitosan (Figure 3). The dissociation degree (DP) of chitosan depending on $\mathrm{pH}$ was calculated from Equation (5) and it was calculated using $\mathrm{pK}_{\mathrm{a}}=6.2$. The degree of chitosan chain ionization progressively decreased with an increase in $\mathrm{pH}$ from 2 to 12, with a large drop observed between $\mathrm{pH} 6.0$ and 7.5 (Figure 3). This decrease would, theoretically, result in a progressive reduction of the electrostatic repulsion between chitosan chains promoting their flexibility and agglomeration at a higher $\mathrm{pH}$ [34]. The $\mathrm{pK}_{\mathrm{a}}$ is the $\mathrm{pH}$ of the inflexion point of the curve (point indicated in the Figure 3). The reason for the $\mathrm{pH}$-dependency is the protonation/deprotonation of the $-\mathrm{NH}_{3}{ }^{+}$group in chitosan.

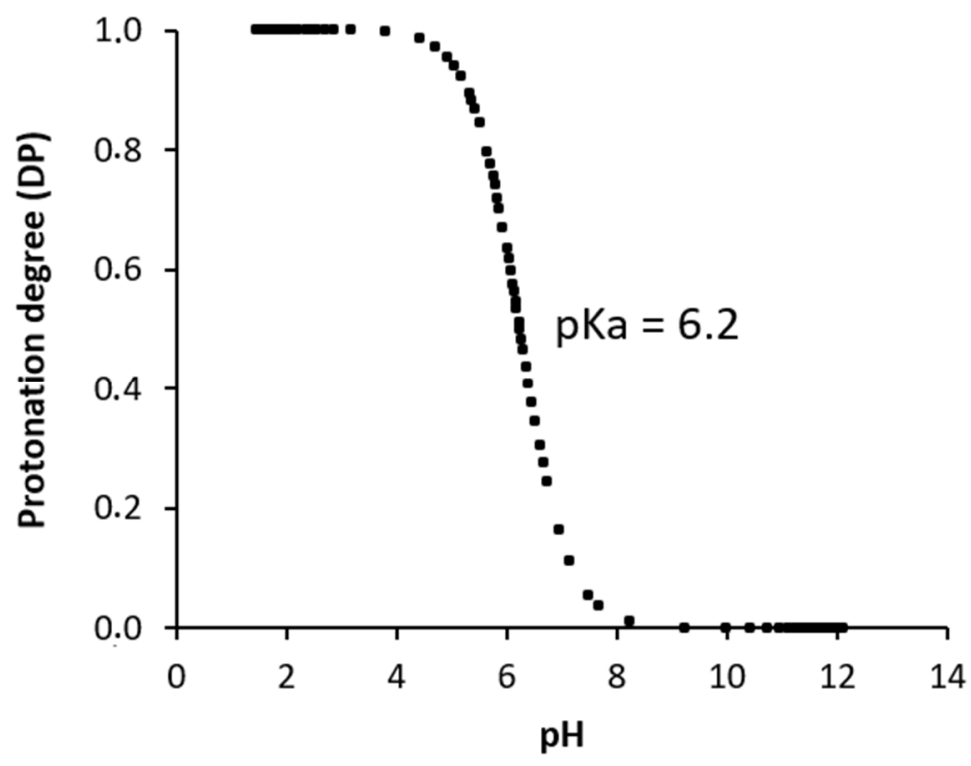

Figure 3. Protonation degree curve of chitosan at $\mathrm{pH}$ 2.0-12.0.

\subsection{Fourier Transform Infrared (FTIR) Spectroscopy}

Figure 4 shows the FTIR absorption spectra of Chitosan-CGNA and commercial chitosan. The spectral range between 4000 and $1750 \mathrm{~cm}^{-1}$ has been omitted because chitosan does not present vibrational bands in that range. Both spectra of chitosan powders show the 
characteristic bands of chitosan previously reported by other authors [35]. For the analysis, the spectra have been separated in two characteristics regions; Region I $\left(1600-1700 \mathrm{~cm}^{-1}\right)$ which is traditionally assigned to proteins, and Region II $\left(1200-800 \mathrm{~cm}^{-1}\right)$ which is typically assigned to polysaccharides. Regarding the Region I, the spectra did not show differences between Chitosan-CGNA and commercial chitosan. Thus, both samples showed the characteristic amide I band at $1656 \mathrm{~cm}^{-1}$, which occurs at similar wavelengths in polyamides and proteins [36,37]. It is commonly assigned to stretching of the $\mathrm{C}=\mathrm{O}$ group hydrogen bonded to $\mathrm{N}-\mathrm{H}$ of the neighbouring intra-sheet chains [37].
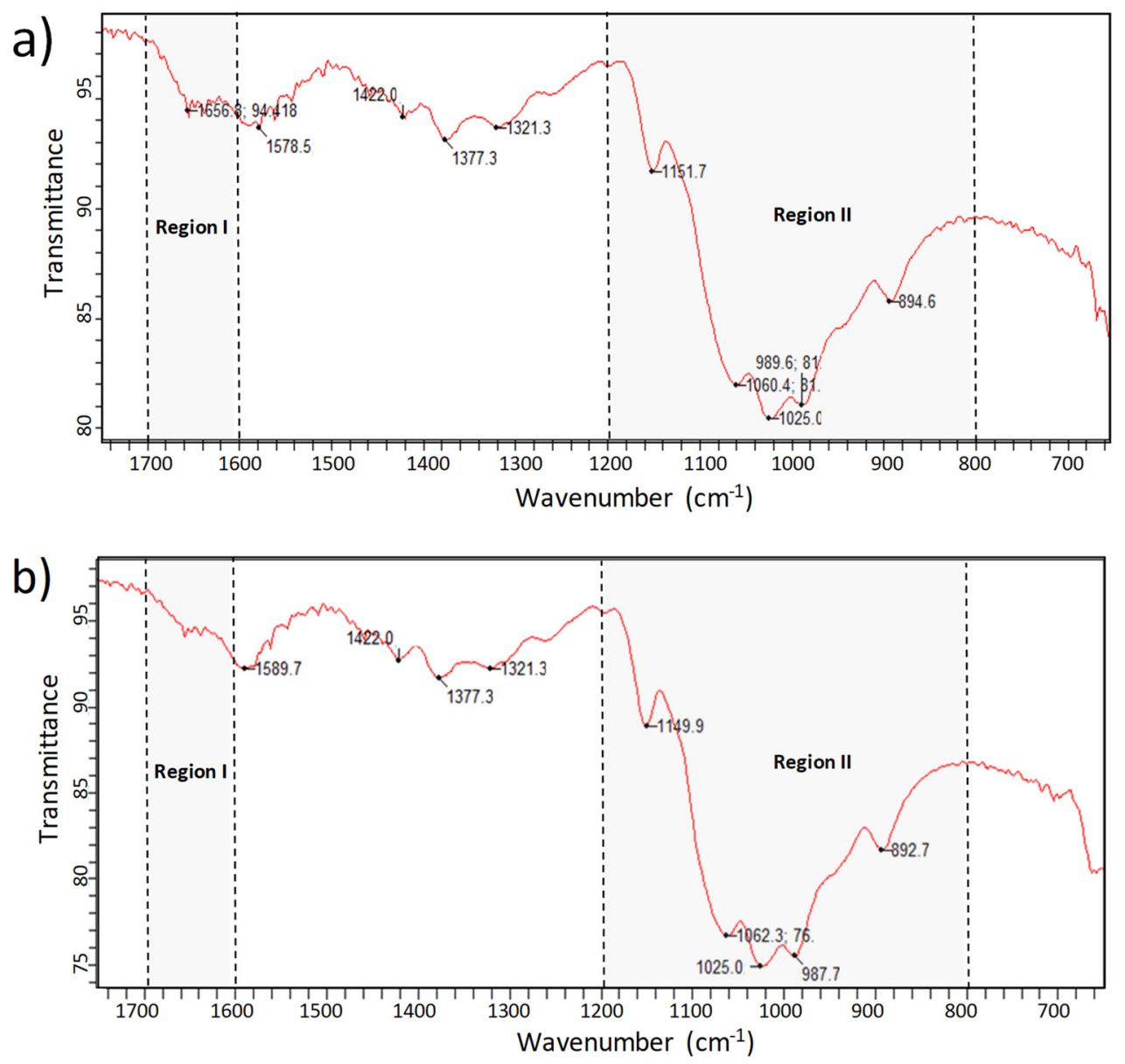

Figure 4. FTIR spectrum of (a) Chitosan-CGNA; and (b) commercial chitosan.

Another characteristic band of $-\mathrm{NH}_{2}$ bending found in chitosan is at $1580 \mathrm{~cm}^{-1}$. In both samples this band shifted to $1578 \mathrm{~cm}^{-1}$ for Chitosan-CGNA and $1589 \mathrm{~cm}^{-1}$ for commercial chitosan. The other characteristic bands of $\mathrm{CH}_{\mathrm{n}}$ groups at $1420 \mathrm{~cm}^{-1}\left(\mathrm{CH}_{2}\right.$ deformation), $1380 \mathrm{~cm}^{-1}$ (- $\mathrm{CH}_{3}$ symmetric deformation), and $1320 \mathrm{~cm}^{-1}$ (amide III and $\mathrm{CH}_{2}$ wagging) were shifted in both samples to $1422 \mathrm{~cm}^{-1}, 1377 \mathrm{~cm}^{-1}$, and $1321 \mathrm{~cm}^{-1}$, respectively.

Meanwhile, the absorption bands in the Region II (1200-800 $\left.\mathrm{cm}^{-1}\right)$ show slight differences. This region belongs to the glycosidic ring, in particular, the band at $1156 \mathrm{~cm}^{-1}$ corresponds to the glycosidic linkage. This characteristic chitosan band was shifted to $1151 \mathrm{~cm}^{-1}$ for Chitosan-CGNA and $1149 \mathrm{~cm}^{-1}$ for commercial chitosan. Therefore, the FTIR spectra exhibited similar bands, suggesting that both chitosan samples share similar chemical compositions.

\subsection{X-ray Diffraction (XRD)}

X-ray diffraction spectra of Chitosan-CGNA and commercial chitosan are shown in Figure 5. The XRD pattern of Chitosan-CGNA exhibited its characteristic crystalline peaks 
at $2 \theta=12.8^{\circ}$ and $23.4^{\circ}$, whereas the commercial chitosan exhibited crystalline peaks at $2 \theta=10.5^{\circ}, 23.4^{\circ}$, and $31.1^{\circ}$. These results show that commercial chitosan has a higher crystalline degree. The reason for having different characteristic peaks might be caused by the source of chitin, as suggested by Kucukgulmez et al. [38] According to Leceta et al. [39], chitosan is a partially crystalline polysaccharide due to its regular chain. The reflection around $10^{\circ}$ can be attributed to crystal forms I and the strongest reflection at $20^{\circ}$ to crystal forms II. Pastor et al. [40] repoted that these two phases correspond to crystalline (less hydrated and harder) zones dispersed in an amorphous (more hydrated and softer) zone and describe the development of crystallinity in chitosan matrices due to the formation of hydrogen bonds between chains.

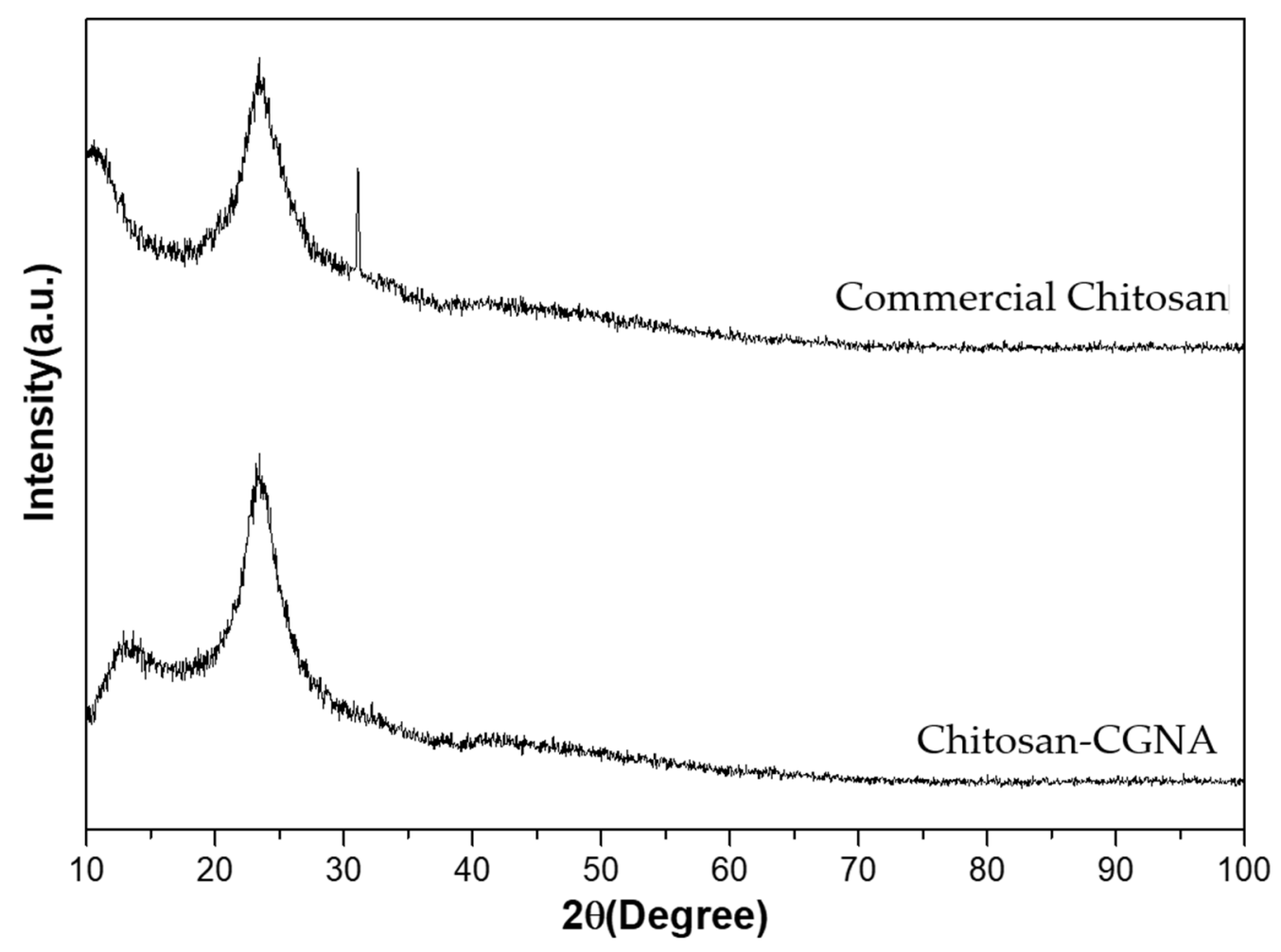

Figure 5. XRD pattern of Chitosan-CGNA and commercial chitosan.

\subsection{Scanning Electron Microscopy (SEM) Analysis}

The morphology of Chitosan-CGNA was studied by SEM at different magnifications and different areas of chitosan (Figure 6). Chitosan-CGNA showed aggregated flakes with a dense and firm structure and without porosity. When the magnification became higher in some parts of chitosan, crumbling flakes were observed with a fibrous structure. In general, chitin and chitosan may be classified into three surface morphologies: (1) with porosity and microfibrillar structure, (2) without porosity or microfibrillar structure, and (3) with only a microfibrillar structure [41]. In addition, the surface morphology chitosan can vary according to the source or organisms. 

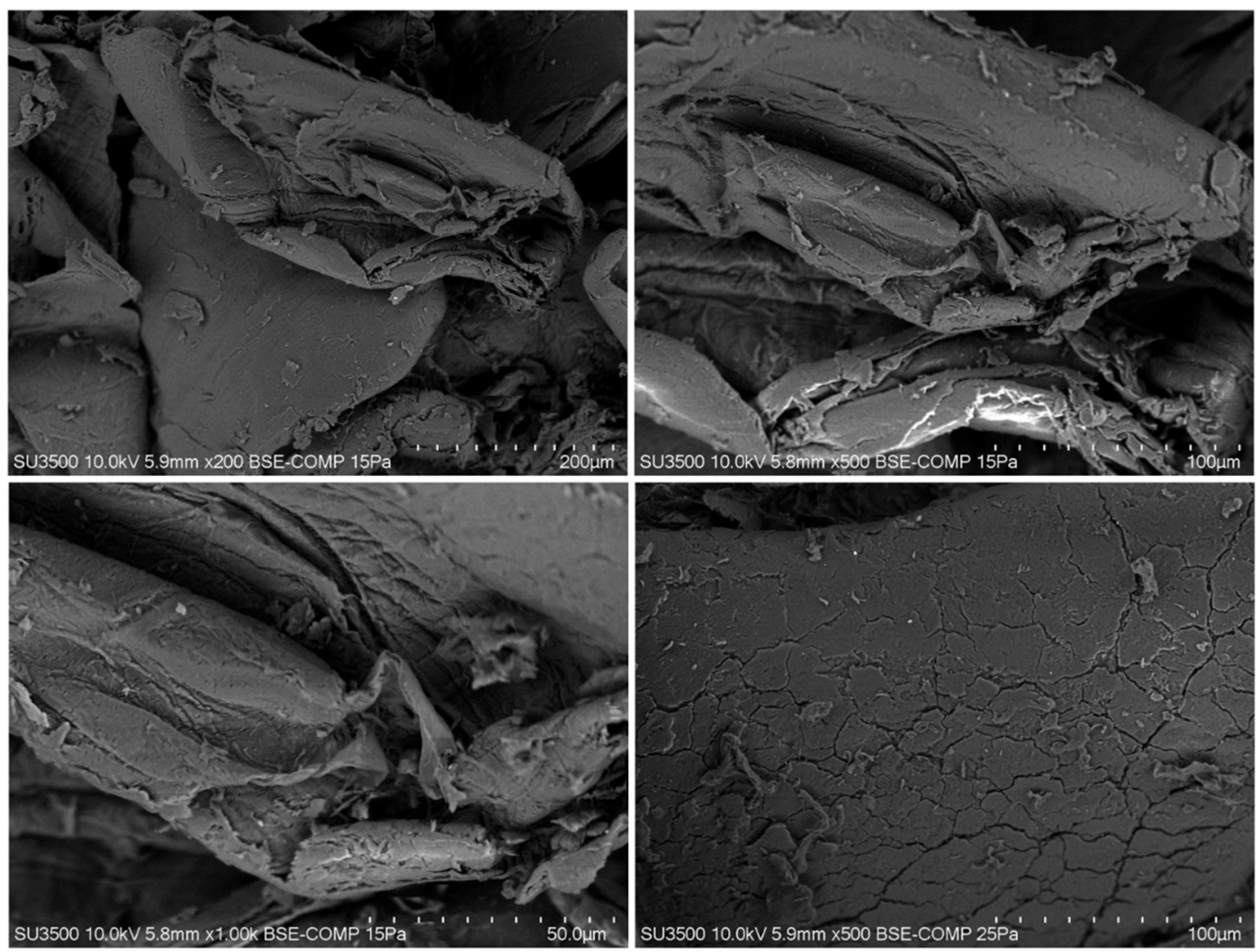

Figure 6. Scanning electron microscopy (SEM) of chitosan extracted from crayfish exoskeleton (Parastacus Pugnax).

\subsection{Effect of $\mathrm{pH}$ and Type of Acid on Solubility of Chitosan Samples}

Chitosan is insoluble in water, aqueous bases, and organic solvents, but soluble in most organic acid solutions with $\mathrm{pH}<6$ [19]. Figure 7 shows the dependence of chitosan's solubility on $\mathrm{pH}$. The chitosan solubility obviously was dependent on $\mathrm{pH}$ variations and the type of acid used in this study (acetic acid, chlorhydric acid, and lactic acid). The results also showed that acetic and lactic acid solutions are a good solvent for chitosan dissolution, reaching the highest biopolymer solubility at $\mathrm{pH} \leq 6$, even though this was at a relatively higher $\mathrm{pH}$ value $(\mathrm{pH}>7)$. The chitosan dissolution with chlorhydric acid was lower at the same conditions. Moreover, the difference of chitosan dissolution was even greater at $\mathrm{pH}$ values higher than 7 , where the highest chitosan solubility was obtained with lactic acid followed by acetic acid and $\mathrm{HCl}$. This indicates that the $\mathrm{pH}$ value is not the only dominant factor in the dissolution of chitosan. Consequently, it is concluded that a lower $\mathrm{pH}$ does not necessarily lead to the greater dissolution of chitosan, implying that the mechanism of chitosan dissolution is not the only protonation of the amino group, but may include interactions between chitosan and the acid as well. According to Chen et al. [42], the most used solvent for chitosan dissolution has been the acetic acid solution. It is a monoacid (with only one carboxylic group), and only serves as a proton donor in solution. In addition to acetic acid, there are many kinds of natural carboxylic acids, such as lactic acid, tartaric acid, and citric acid. Some binary and tertiary acids can react with two or more amino groups on separate chitosan chains, causing cross-linking of the chitosan into a large structure. 


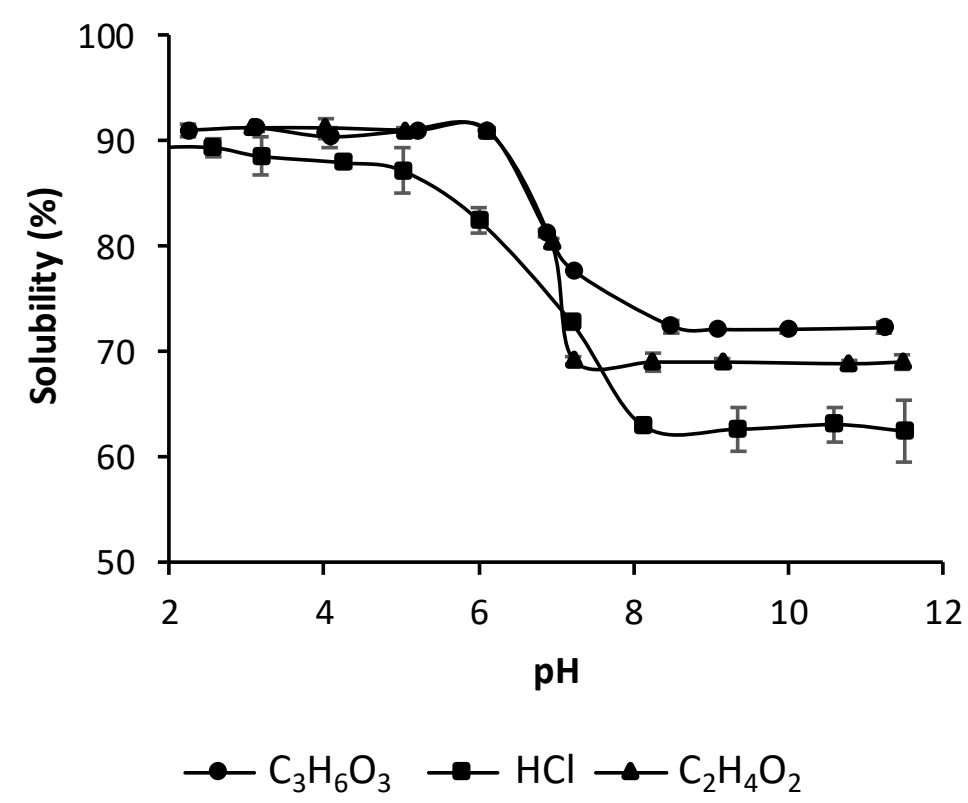

Figure 7. Solubility of Chitosan-CGNA with different acids at $\mathrm{pH}$ range from 2 to 11 . Results are presented as means \pm standard deviations $(n=3)$.

\subsection{DPPH Radical Scavenging Ability}

Figure 8 shows the DPPH radical scavenging activities of Chitosan-CGNA. Ascorbic acid was used as a control in this study. The chitosan sample shows different scavenging abilities in a dose-dependent manner. For Chitosan-CGNA, the DPPH scavenging abilities ranging from $0 \%$ to $44.57 \%$ at varying concentrations $(0-10 \mathrm{mg} / \mathrm{mL})$; this range was higher than the commercial chitosan sample (0-29.58\%). According to Huang and Tsai [8], the DPPH radical scavenging effect of chitosan is related to the DD where a high value has a better antioxidant potential due to the number of free amino groups in its structure.

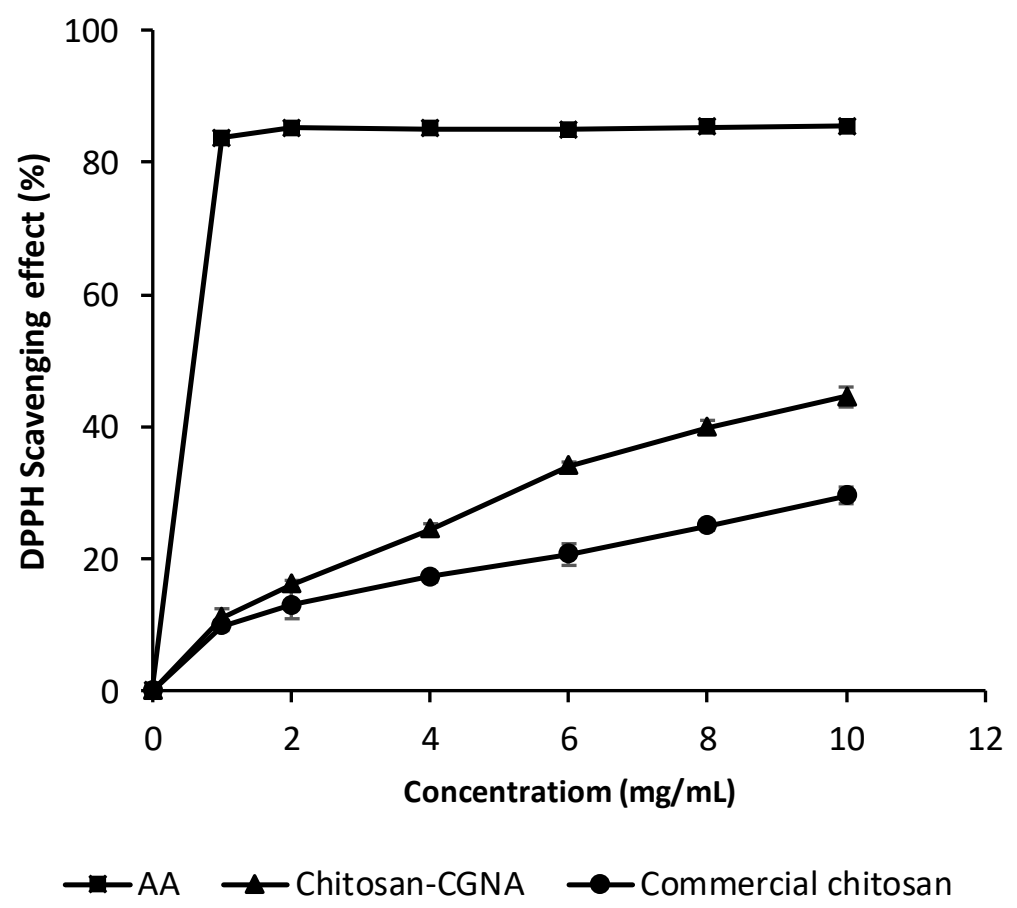

Figure 8. DPPH radical scavenging effect of chitosan samples. Results are presented as means \pm standard deviations $(n=3)$. AA: ascorbic acid. 
Therefore, the scavenging mechanism of chitosan could be explained by its active hydrogen atoms reacting with hydroxyl and superoxide anion radicals to form a stable macromolecule radical [8]. Kim and Thomas [43], reported that the scavenging mechanism of chitosan is related to the fact that the free radicals can react with the hydrogen ion from the ammonium ions $\left(-\mathrm{NH}_{3}{ }^{+}\right)$to form a stable molecule. The $\left(-\mathrm{NH}_{3}{ }^{+}\right)$has been formed by the amine group absorbing a hydrogen ion from the solution.

\subsection{Antibacterial Activity}

The chitosan antibacterial activity is influenced by several factors, such as temperature, $\mathrm{pH}$, molecular weight $(\mathrm{Mw})$, degrees of deacetylation (DD), chitosan concentration, type of microorganism, growth phase of the microorganism and culture medium composition [44-46].

Table 2 shows the Minimum inhibitory concentration (MIC) and the Minimum bactericidal concentration (MBC) of the Chitosan-CGNA and commercial chitosan against Gram-positive and Gram-negative bacteria. The results suggest that the antibacterial activity of Chitosan-CGNA and commercial chitosan have a slight trend toward Gram-positive than Gram-negative bacteria. This behavior agrees with No et al. [44] for chitosan samples between $746-470 \mathrm{kDa}$.

Table 2. Minimum Inhibitory Concentration (MIC) and Minimum Bactericidal Concentration (MBC) of chitosan.

\begin{tabular}{ccccc}
\hline \multirow{2}{*}{ Bacteria } & \multicolumn{2}{c}{ Chitosan-CGNA } & \multicolumn{2}{c}{ Commercial Chitosan } \\
\cline { 2 - 5 } & MIC $(\mathbf{m g} / \mathbf{m L})$ & MBC $(\mathbf{m g} / \mathbf{m L})$ & MIC $(\mathbf{m g} / \mathbf{m L})$ & MBC $(\mathbf{m g} / \mathbf{m L})$ \\
\hline E. coli & 0.16 & 0.31 & 0.31 & 0.63 \\
S. typhimurium & 0.04 & 0.04 & 0.63 & 0.63 \\
P. aeruginosa & 0.04 & 0.04 & 0.02 & 0.02 \\
S. aureus & 0.04 & 0.04 & 0.005 & 0.02 \\
L. monocytogenes & 0.08 & 0.16 & 0.63 & 1.25 \\
E. faecalis & 0.04 & 0.04 & 0.02 & 0.15 \\
\hline
\end{tabular}

On the other hand, the results showed that the Chitosan-CGNA concentration to inhibit the E. coli, S. typhimurium, and L. monocytogenes growth was lower than the concentration of commercial chitosan. Whereas, the MIC and MBC of Chitosan-CGNA was higher than commercial chitosan with S. aureus, E. faecalis and P. aeruginosa. These results do not allow the suggestion that Chitosan-CGNA has a higher inhibitory or bactericidal activity than commercial chitosan but shed light on its potential use.

Previous studies performed with similar bacterial strains showed different MIC and MBC values [46-48]. According to Li and Zhuang [45], many factors can influence the antibacterial activity of chitosan. In this study, the Chitosan-CGNA showed a MIC value lower than other chitosan samples in E. coli [44,49], S. aureus [44,49], P. aeruginosa [49], and L. monocytogenes [44]. Whereas, with E. coli, S. aureus, and S. typhimurium, the MIC values of Chitosan-CGNA were higher than other reports [48]. The MBC values reported for Chitosan-CGNA were different to those previously reported; however, the MBC values of S. typhimurim, and S. aureus were equivalent to those reported by Kong et al. [48]

The differences in the MIC and MBC values between Chitosan-CGNA and others chitosan previously reported can be explained by different factors including $\mathrm{pH}$, molecular weight, degrees of deacetylation, viscosity, all factors that influence the antibacterial activity of the chitosan [45-48].

The MIC and MBC determinations show that the Chitosan-CGNA has an antibacterial activity against all the bacteria used in this study. The inhibitory and bactericidal effect was evident at different concentrations of Chitosan-CGNA and depended on the bacterial species. These results allow the suggestion that Chitosan-CGNA could be used in applications against bacteria relevant to the food industry. 


\section{Conclusions}

In the present study, chitosan from crayfish exoskeleton (P. pugnax) was produced and was physico-chemically characterized. The results revealed that chitosan extracted from the crayfish exoskeleton is a good quality biopolymer with similar properties to commercial chitosan. The chitosan had a medium molecular weight and a high DD. Moreover, the results suggest that DD could have largely influenced the physicochemical and biological properties of chitosan. Regarding the antioxidant activities, this study demonstrated the higher reducing ability and hydroxyl radical scavenging activity in Chitosan-CGNA than those in commercial chitosan.

In addition, Chitosan-CGNA showed antimicrobial activity against both Gram-positive and Gram-negative bacterium strains. Thus, this new ingredient could be used as a promising antimicrobial agent.

Hence, the present study suggests that the P. pugnax crayfish exoskeleton can be considered as a potential source to produce chitosan for different applications.

Supplementary Materials: The following are available online at https:/ /www.mdpi.com/article/10 .3390/polym13142304/s1, Figure S1: Minimum inhibitory concentration (MIC), Figure S2: Minimum Bactericidal Concentration (MBC).

Author Contributions: Conceptualization, C.B.-D. and T.B.; formal analysis, M.O.-N.; funding acquisition, C.B.-D.; investigation, C.B.-D., M.O.-N., J.L.P., T.B., Y.M.-R. and F.A.-B.; methodology, J.L.P., T.B., Y.M.-R., F.A.-B. and M.B.; project administration, C.B.-D.; resources, C.B.-D., J.L.P. and M.B.; supervision, C.B.-D.; validation, M.O.-N.; visualization, C.B.-D.; writing-original draft, C.B.-D., Y.M.-R. and F.A.-B.; writing-review and editing, C.B.-D., M.O.-N. and J.L.P. All authors have read and agreed to the published version of the manuscript.

Funding: This research was supported by ANID through FONDECYT project $N^{\circ} 1210136$.

Institutional Review Board Statement: Not applicable.

Informed Consent Statement: Not applicable.

Data Availability Statement: Not applicable.

Acknowledgments: We acknowledge the Regional Government from La Araucanía Region (Chile) and "Cooperativa Agrícola Cacike Juan Currimil de Lolocura Ltd.a". We also acknowledge the CGNA's chemical unit for their valuable technical assistance.

Conflicts of Interest: The authors declare no conflict of interest.

\section{References}

1. Ibarra, M.A.; Arana, P.M. Biological parameters of the burrowing crayfish, Parastacus pugnax (Poeppig, 1835), in Tiuquilemu, Bío-Bío Region, Chile. Lat. Am. J. Aquat. Res. 2012, 40, 418-427. [CrossRef]

2. Rudolph, E. Parastacus pugnax (Poeppig, 1835) (Crustacea, Decapoda, Parastacidae): Biological knowledge, extraction pressure and culture perspectives. Lat. Am. J. Aquat. Res. 2017, 41, 611-632. [CrossRef]

3. Mohan, K.; Muralisankar, T.; Jayakumar, R.; Rajeevgandhi, C. A study on structural comparisons of $\alpha$-chitin extracted from marine crustacean shell waste. Carbohydr. Polym. Technol. Appl. 2021, 2, 100037.

4. Avelelas, F.; Horta, A.; Pinto, L.F.V.; Cotrim-Marques, S.; Marques-Nunes, P.; Pedrosa, R.; Leandro, S.M. Antifungal and antioxidant properties of chitosan polymers obtained from nontraditional Polybius henslowii sources. Mar. Drugs. 2019, 17, 239. [CrossRef]

5. Abo-Elsoud, M.M.; El-Kady, E.M. Current trends in fungal biosynthesis of chitin and chitosan. Bull. Natl. Res. Cent. 2019, 43, 1-12. [CrossRef]

6. Wang, X.Y.; Heuzey, M.C. Chitosan-based conventional and pickering emulsions with long-term stability. Langmuir 2016, 32, 929-936. [CrossRef]

7. Joseph, S.M.; Krishnamoorthy, S.; Paranthaman, R.; Moses, J.A.; Anandharamakrishnan, C. A review on source-specific chemistry, functionality, and applications of chitin and chitosan. Carbohydr. Polym. Technol. Appl. 2021, 2, 100036.

8. Huang, Y.-L.; Tsai, Y.-H. Extraction of chitosan from squid pen waste by high hydrostatic pressure: Effects on physicochemical properties and antioxidant activities of chitosan. Int. J. Biol. Macromol. 2020, 160, 677-687. [CrossRef] [PubMed]

9. Ribeiro, A.G.; Viana, M.; Hattori, G.; Constantino, V.R.; Perotti, G. Extraction and characterization of biopolymers from exoskeleton residues of the amazon crab dilocarcinus pagei. Braz. J. Environ. Sci. 2018, 50, 97-111. [CrossRef] 
10. Muxika, A.; Etxabide, A.; Uranga, J.; Guerrero, P.; de la Caba, K. Chitosan as a bioactive polymer: Processing, properties and applications. Int. J. Biol. Macromol. 2017, 10, 1358-1368. [CrossRef] [PubMed]

11. Jung, J.; Zhao, Y. Comparison in antioxidant action between $\alpha$-chitosan and $\beta$-chitosan at a wide range of molecular weight and chitosan concentration. Bioorg. Med. Chem. 2012, 20, 2905-2911. [CrossRef]

12. Goy, R.C.; Morais, S.T.B.; Assis, O.B.G. Evaluation of the antimicrobial activity of chitosan and its quaternized derivative on $E$. coli and S. aureus growth. Rev. Bras. Farmacog. 2016, 26, 122-127. [CrossRef]

13. Philibert, T.; Lee, B.H.; Fabien, N. Current status and new perspectives on chitin and chitosan as functional biopolymers. Appl. Biochem. Biotechnol. 2017, 181, 1314-1337. [CrossRef] [PubMed]

14. Bradford, M.M. A rapid and sensitive method for the quantitation of microgram quantities of protein utilizing the principle of protein-dye binding. Anal. Biochem. 1976, 72, 248-254. [CrossRef]

15. Qin, C.; Li, H.; Xiao, Q.; Liu, Y.; Zhu, J.; Du, Y. Water-solubility of chitosan and its antimicrobial activity. Carbohydr. Polym. 2006, 63, 367-374. [CrossRef]

16. Aliasghari, A.; Khorasgani, M.R.; Vaezifar, S.; Rahimi, F.; Younesi, H.; Khoroushi, M. Evaluation of antibacterial efficiency of chitosan and chitosan nanoparticles on cariogenic streptococci: An in vitro study. Iran. J. Microbiol. 2016, 8, 93-100. [PubMed]

17. Su, Z.; Han, Q.; Zhang, F.; Meng, X.; Liu, B. Preparation, characterization and antibacterial properties of 6-deoxy-6-arginine modified chitosan. Carbohydr. Polym. 2020, 230, 115635. [CrossRef] [PubMed]

18. Opazo-Navarrete, M.; Tabilo-Munizaga, G.; Vega-Gálvez, A.; Miranda, M.; Pérez-Won, M. Effects of high hydrostatic pressure (HHP) on the rheological properties of Aloe vera suspensions (Aloe barbadensis Miller). Innov. Food Sci. Emerg. Technol. 2012, 16, 243-250. [CrossRef]

19. Rasweefali, M.K.; Sabu, S.; Sunooj, K.V.; Sasidharan, A.; Martin-Xavier, K.A. Consequences of chemical deacetylation on physicochemical, structural and functional characteristics of chitosan extracted from deep-sea mud shrimp. Carbohydr. Polym. Technol. Appl. 2021, 2, 100032.

20. Yuan, Y.; Chesnutt, B.M.; Haggard, W.O.; Bumgardner, J.D. Deacetylation of chitosan: Material characterization and in vitro evaluation via albumin adsorption and pre-osteoblastic cell cultures. Materials 2011, 4, 1399-1416. [CrossRef]

21. Ali, M.; Shakeel, M.; Mehmood, K. Extraction and characterization of high purity chitosan by rapid and simple techniques from mud crabs taken from Abbottabad. Pak. J. Pharm. Sci. 2019, 32, 171-175. [PubMed]

22. Baskar, D.; Sampath-Kumar, T.S. Effect of deacetylation time on the preparation, properties and swelling behavior of chitosan films. Carbohydr. Polym. 2009, 78, 767-772. [CrossRef]

23. Lv, S.H. Biopolymers and Biotech Admixtures for Eco-Efficient Construction Materials; High-Performance Superplasticizer Based on Chitosan; Woodhead Publishing: Cambridge, UK, 2016; pp. 131-148.

24. Weißpflog, J.; Vehlow, D.; Müller, M.; Kohn, B.; Scheler, U.; Boye, S.; Schwarz, S. Characterization of chitosan with different degree of deacetylation and equal viscosity in dissolved and solid state-Insights by various complimentary methods. Int. J. Biol. Macromol. 2021, 171, 242-261. [CrossRef] [PubMed]

25. Younes, I.; Hajji, S.; Frachet, V.; Rinaudo, M.; Jellouli, K.; Nasri, M. Chitin extraction from shrimp shell using enzymatic treatment. Antitumor, antioxidant and antimicrobial activities of chitosan. Int. J. Biol. Macromol. 2014, 69, 489-498. [CrossRef]

26. Minh, N.C.; Hoa, N.V.; Trang, S.T. Handbook of Chitin and Chitosan; Preparation, Properties, and Application of Low-MolecularWeight Chitosan; Elsevier: Amsterdam, The Netherlands, 2020; pp. 453-471.

27. Costa, C.N.; Teixeira, V.G.; Delpech, M.C.; Souza, J.V.S.; Costa, A.S. Viscometric study of chitosan solutions in acetic acid/sodium acetate and acetic acid/sodium chloride. Carbohydr. Polym. 2015, 133, 245-250. [CrossRef] [PubMed]

28. Shirvan, A.R.; Shakeri, M.; Bashari, A. The Impact and Prospects of Green Chemistry for Textile Technology; Recent Advances in Application of Chitosan and Its Derivatives in Functional Finishing of Textiles; Elsevier: Amsterdam, The Netherlands, 2019; pp. 107-133.

29. Cho, Y.I.; No, H.K.; Meyers, S.P. Physicochemical characteristics and functional properties of various commercial chitin and chitosan products. J. Agric. Food Chem. 1998, 46, 3839-3843. [CrossRef]

30. Ssekatawa, K.; Byarugaba, D.K.; Wampande, E.M.; Moja, T.N.; Nxumalo, E.; Maaza, M.; Sackey, J.; Ejobi, F.; Kirabira, J.B Isolation and characterization of chitosan from Ugandan edible mushrooms, Nile perch scales and banana weevils for biomedical applications. Sci. Rep. 2021, 11, 4116. [CrossRef] [PubMed]

31. Filion, D.; Lavertu, M.; Buschmann, M.D. Ionization and Solubility of Chitosan Solutions Related to Thermosensitive Chitosan/Glycerol-Phosphate Systems. Biomacromolecules 2007, 8, 3224-3234. [CrossRef]

32. Pérez-Álvarez, L.; Ruiz-Rubio, L.; Vilas-Vilela, J.L. Determining the deacetylation degree of chitosan: Opportunities to learn instrumental techniques. J. Chem. Educ. 2018, 95, 1022-1028. [CrossRef]

33. Wang, Q.Z.; Chen, X.G.; Liu, N.; Wang, S.X.; Liu, C.S.; Meng, X.H.; Liu, C.G. Protonation constants of chitosan with different molecular weight and degree of deacetylation. Carbohydr. Polym. 2006, 65, 194-201. [CrossRef]

34. Wang, X.-Y.; Wang, J.; Rousseau, D.; Tang, C.-H. Chitosan-stabilized emulsion gels via pH-induced droplet flocculation. Food Hydrocoll. 2020, 105, 105811. [CrossRef]

35. Mauricio-Sánchez, R.A.; Salazar, R.; Luna-Bárcenas, J.G.; Mendoza-Galván, A. FTIR spectroscopy studies on the spontaneous neutralization of chitosan acetate films by moisture conditioning. Vib. Spectrosc. 2018, 94, 1-6. [CrossRef]

36. Vidal, B.C.; Mello, M.L.S. Collagen type I amide I band infrared spectroscopy. Micron 2011, 42, 283-289. [CrossRef]

37. Rinaudo, M. Chitin and chitosan: Properties and applications. Prog. Polym. Sci. 2006, 31, 603-632. [CrossRef] 
38. Kucukgulmez, A.; Celik, M.; Yanar, Y.; Sen, D.; Polat, H.; Kadak, A.E. Physicochemical characterization of chitosan extracted from Metapenaeus stebbingi shells. Food Chem. 2011, 126, 1144-1148. [CrossRef]

39. Leceta, I.; Guerrero, P.; Ibarburu, I.; Dueñas, M.T.; de la Caba, K. Characterization and antimicrobial analysis of chitosan-based films. J. Food Eng. 2013, 116, 889-899. [CrossRef]

40. Pastor, P.; Sánchez-González, L.; Chiralt, A.; Cháfer, M.; González-Martínez, C. Physical and antioxidant properties of chitosan and methylcellulose based films containing resveratrol. Food Hydrocoll. 2013, 30, 272-280. [CrossRef]

41. Kaya, M.; Baran, T.; Mentes, A.; Asaroglu, M.; Sezen, G.; Tozak, K.O. Extraction and Characterization of $\alpha$-Chitin and Chitosan from Six Different Aquatic Invertebrates. Food Biophys. 2014, 9, 145-157. [CrossRef]

42. Chen, P.-H.; Hwang, Y.-H.; Kuo, T.-Y.; Liu, F.-H.; Lai, J.-Y.; Hsieh, H.-J. Improvement in the properties of chitosan membranes using natural organic acid solutions as solvents for chitosan dissolution. J. Med. Biol. Eng. 2007, 27, 23-28.

43. Kim, K.W.; Thomas, R.L. Antioxidative activity of chitosans with varying molecular weights. Food Chem. 2007, 101, 308-313. [CrossRef]

44. No, H.K.; Park, N.Y.; Lee, S.H.; Meyers, S.P. Antibacterial activity of chitosans and chitosan oligomers with different molecular weights. Int. J. Food Microbiol. 2002, 74, 65-72. [CrossRef]

45. Li, J.; Zhuang, S. Antibacterial activity of chitosan and its derivatives and their interaction mechanism with bacteria: Current state and perspectives. Euro. Polymer J. 2020, 138, 109984. [CrossRef]

46. Wang, M.; Bi, S.; Pang, J.; Zhou, Z.; Qin, D.; Wang, H.; Cheng, X.; Chen, X. Precise quantification of the antibacterial activity of chitosan by NB medium neutralizer. J. Mater. Sci.Technol. 2021, 70, 224-232. [CrossRef]

47. Wang, M.; Bi, S.; Qin, D.; Su, C.; Wang, H.; Chen, X. Quantitative evaluation of the antibacterial effectiveness and efficiency of chitosan considering the effect of neutralization. Carbohydr. Polym. 2021, 265, 117918. [CrossRef] [PubMed]

48. Kong, M.; Chen, X.G.; Xing, K.; Park, H.J. Antimicrobial properties of chitosan and mode of action: A state of the art review. Int. J. Food Microbiol. 2010, 144, 51-63. [CrossRef]

49. Balicka-Ramisz, A.; Wojtasz-Pajak, A.; Pilarczyk, B.; Ramisz, A.; Laurans, L. Antibacterial and antifungal activity of chitosan. In Proceedings of the ISAH 2005, Warsaw, Poland, 4-8 September 2005; Volume 2, pp. 406-408. 